\title{
Genetic polymorphisms and cervical cancer development: ATM G5557A and p53bp1 C1236G
}

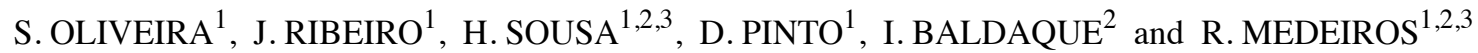 \\ ${ }^{1}$ Molecular Oncology Group, and ${ }^{2}$ Molecular Biology Laboratory of Virology Service, Portuguese Institute \\ of Oncology of Porto, Rua Dr António Bernardino Almeida, 4200-072 Porto; ${ }^{3}$ Abel Salazar Institute \\ for the Biomedical Sciences (ICBAS), Largo Professor Abel Salazar 2, 4099-003 Porto, Portugal
}

Received July 18, 2011; Accepted August 29, 2011

DOI: $10.3892 /$ or.2011.1609

\begin{abstract}
Persistent infections by high-risk types of human papillomavirus (HPV) have been established as the etiological agent of cervical cancer. The integration of the HPV genome into the host genome is a crucial step in cervical carcinogenesis, although, correct activation of DNA damage repair pathways will avoid the development of cancer. Recent data indicate that several polymorphisms of key regulators from the DNA damage repair pathway (i.e. 53BP1 and ATM) are associated with cancer development susceptibility. We have developed a hospitalbased retrospective study considering 429 cervical specimens from women with different cervical lesions including invasive carcinoma. This study aimed to evaluate the role of the ATM $\mathrm{D} 1853 \mathrm{~N}(5557 \mathrm{G}>\mathrm{A})$ and 53bp1 D353E (1236C $>\mathrm{G})$ polymorphisms in the development of cervical cancer, using TaqMan ${ }^{\circledR}$ SNP Genotyping Assays. Statistical analysis revealed that ATM 5557GG homozygous individuals (OR=1.94; $\mathrm{p}=0.044)$ are at increased risk of developing LSIL, while for the 53BP1 $1236 \mathrm{C}>\mathrm{G}$ polymorphism no association was found. Nevertheless, we observed a tendency for an increased risk of LSIL in 53BP1 1236C allele carriers (OR=1.63; $\mathrm{p}=0.069)$. Logistic regression adjusted for age revealed no significant differences from the non-adjusted analysis. This is the first study to evaluate the role of ATM G5557A and P53BP1 C1236G polymorphisms in cervical cancer susceptibility. This study reveals a possible trend of both polymorphisms for a genetic susceptibility pattern of cervical cancer development. Hence, our results may be of interest for future understanding of the progression of cervical cancer.
\end{abstract}

\section{Introduction}

Cervical cancer is the third most common cancer in women with over 500,000 new cases and over 275,000 deaths in 2008

Correspondence to: Dr Hugo Sousa, Molecular Oncology Group, CI, Portuguese Institute of Oncology of Porto, FG, EPE, Rua Dr António Bernardino Almeida, 4200-072 Porto, Portugal

E-mail: hugomls@gmail.com

Key words: ataxia-telangiectasia-mutated protein, p53bp1, genetic polymorphism, DNA damage, human papillomavirus, cervical cancer according to the World Health Organization (1). Incidence and mortality rates are very different among developed and developing countries, being extremely common in Central and South America, Eastern Africa and South-East Asia (2,3). In Portugal, incidence and mortality rates have been decreasing in the past ten years, and most recently data point to 12.2 and 3.6 per 100,000 , respectively (1).

Persistent infection by the oncogenic types of the human papillomavirus (HPV) was established as the main etiological factor for cervical cancer development (4-8). Nevertheless, despite the main role of HPV, epidemiological studies revealed that several co-factors may be implicated in the carcinogenesis model, such as: measures of sexual activity (number of sexual partners, age at first sexual intercourse and sexual behaviour of partners), parity ( $>3$ children), tobacco and alcohol consumption, co-infection with other sexually transmitted agents, as well as immunologic and host genetic factors (7-13)

The integration of the HPV genome in host genome is a crucial event for cell de-regulation towards the development of cervical cancer. Viral DNA integration is only possible with the formation of DNA double-strand breaks (DSBs), which will allow the assimilation of the viral genome linearized into the host genome (14-17). Some studies suggest that the regulation of this process may be of extreme importance in the prevention of cancer development (18).

DSBs are one of the most serious threats to the integrity of the eukaryotic genome and an efficient response to DNA damage is essential for the maintenance of genome integrity, preventing the accumulation of errors (18). Therefore, several proteins from a complex system of different mechanisms are activated to repair the genome (19-21).

When a DSB occurs, p53 binding protein 1 (p53bp1) migrates into its site, promoting the interaction with several proteins involved in DNA repair and/or DNA damagesignalling pathways, including genome guardian protein, p53 $(19,22-25)$. In fact, p53bp1 has been described as the activator of the ataxia-telangiectasia-mutated protein (ATM) response to DNA damage $(26,27)$.

ATM is the key protein in DMA damage response upon DSBs, leading to cell cycle checkpoint activation, DNA repair, gene transcription and in severe cases to apoptosis $(28,29)$. ATM is an important member of the serine/threonine protein kinases 
family, and several mutations have been associated with cancer development (30-34).

Previous reports have shown that single nucleotide polymorphism (SNP) on both these proteins may be correlated with DSB recognition and cell capacity to repair DNA. An SNP on nucleotide 5557 (exon 9) of ATM, characterized by a G to A transition leads to an amino acid change at position 1853 of the protein (D1853N) (35). This polymorphism was described as affecting an exonic splicing enhancer (ESE), suggesting a possible alteration on the normal splicing of exon 9 of the ATM gene and therefore a production of a less effective protein (36). Previous studies have reported the influence of this polymorphism in the development of several types of cancer (37-42). Furthermore, from the several polymorphisms identified in the coding and promoter regions of the 53BP1 gene (43), a transition $\mathrm{C} \rightarrow \mathrm{G}$ at the nucleotide 1236 (exon 9), which leads to an amino acid change at position 353 of the protein (D353E) (44), has previously been associated with the development of breast cancer (43). The aim of this study was to evaluate the role of the ATM D1853N (5557G >A) and p53bp1 D353E (1236C >G) polymorphisms in the development of cervical cancer in Portugal.

\section{Materials and methods}

Cases and specimens. This study was performed with exfoliated cervical cells collected with cytobrush at the Gynaecological Service of the Portuguese Institute of Oncology of Porto from 429 inpatient women with median age of $45 \pm 13.73$ years. Samples were used for liquid-based cytology for cytological classification according to the Bethesda classification: 280 normal (45.0 \pm 13.23 years), 70 low-grade intraepithelial squamous lesions (44.0 \pm 14.82 years), 70 high-grade intraepithelial squamous lesions including in situ carcinoma (45 \pm 13.7 years), and 9 ICC (47.0 \pm 18.85 years) (Table I).

DNA extraction. DNA was extracted from $200 \mu \mathrm{l}$ of exfoliated cervical cells using High Pure ${ }^{\circledR}$ Viral Nucleic Acid Roche (Roche Applied Science, Indianapolis, USA) according to the manufacturer's instructions.

SNP genotyping. ATM D1853N (5557G>A) and p53bp1 D535E $(1236 \mathrm{C}>\mathrm{G})$ polymorphisms were genotyped using TaqMan SNP genotyping assays (C__26487857_10 and C___2944794_10, respectively) from Applied Biosystems (Foster City, CA, USA). Reactions were performed on an Applied Biosystems 7300 real-time PCR system (Applied Biosystems) with a 5- $\mu$ l final volume mixture containing $1 \mathrm{X}$ TaqMan genotyping master mix (Applied Biosystems), $900 \mathrm{nM}$ of each primer, $200 \mathrm{nM}$ of probes labeled with either FAM or VIC, and $10 \mathrm{ng}$ of extracted DNA. Thermal cycling conditions were: $10 \mathrm{~min}$ at $95^{\circ} \mathrm{C}$ followed by 40 cycles of $15 \mathrm{sec}$ at $95^{\circ} \mathrm{C}$ and $1 \mathrm{~min}$ at $60^{\circ} \mathrm{C}$. Allelic discrimination was performed by measuring end-point fluorescence using ABI PRISM ${ }^{\circledR}$ Sequence Detection System (Version 1.2.3, Applied Biosystems). Results were analyzed by two of the authors, and $10 \%$ were randomly selected and re-submitted to genotyping for confirmation. Concordance of genotypes was $100 \%$ among replicates.

Statistical analysis. Genotypes were tested for the HardyWeinberg equilibrium (HWE) with the public software available
Table I. Characteristics of the study population.

\begin{tabular}{lc}
\hline Cytological classification & Median age $( \pm$ SD) \\
\hline Total $(n=429)$ & $45.0 \pm 13.7$ \\
Normal $(n=280)$ & $45.0 \pm 13.2$ \\
All lesions $(n=149)$ & \\
LSIL ( $=70)$ & $44.0 \pm 14.8$ \\
HSIL/CIS $(n=70)$ & $45.0 \pm 13.7$ \\
ICC $(n=9)$ & $47.0 \pm 18.8$ \\
\hline
\end{tabular}

at http://ihg.gsf.de/. Statistical analysis was performed with the computer software SPSS (Statistical Package for Social Sciences version 16.0) for Mac. Chi-square $\left(\chi^{2}\right)$ analysis was used to compare the categorical variables with a $5 \%$ significance level. Fisher's exact test was used for tables containing cells where values are $<5$ individuals. The odds ratio (OR) and its $95 \%$ confidence interval (CI) were calculated as a measure of the association between the genotypes and clinicopathological parameters by including dichotomous covariates for genotypes. Logistic regression analysis was performed by adjusting for age the risk of cervical carcinoma development.

\section{Results}

53BP1 C1236G polymorphism. Table II shows the distribution of the 53BP1 $1236 \mathrm{G}>\mathrm{C}$ genotypes according to cytological classification. The frequency of the 53BP1 $1236 \mathrm{GG}, \mathrm{GC}$ and CC genotypes were $38.2,45.5$ and $16.3 \%$, respectively. Statistical analysis revealed that there were no significant differences between the genotypes distribution within cervical lesions and cancer $(p>0.050)$, neither when adjusting the analysis for age by logistic regression (data not shown).

ATM G5557A polymorphism. Table III shows the distribution of the ATM G5557A genotypes and their frequencies in cervical specimens. From 429 cases, $71.6 \%$ were found to be homozygous for $\mathrm{G}$ allele, $25.6 \%$ were heterozygous, and $2.8 \%$ were homozygous for A allele. Statistical analysis revealed significant differences between A carriers versus GG homozygous in women with LSIL ( $\mathrm{p}=0.044 ; \mathrm{OR}=1.94 ; 95 \%$ CI 1.01-3.74). Logistic regression adjusting for age revealed no statistical differences (data not shown).

\section{Discussion}

HPV is the etiological agent of cervical cancer and its precursor lesions and viral genome integration into the host genome is considered to be the crucial step of cervical carcinogenesis $(8,9)$. Beyond the genetic events that can affect genome integrity, viral integration is considered to have a high impact on cell de-regulation and its control is extremely important to prevent the development of neoplastic cells $(16,18,45)$.

Viral DNA integration is though to occur by the erratic activation of DNA repair mechanisms upon the formation of DSBs (14-17). The ATM protein is a crucial kinase for cell cycle checkpoints regulation and activation of cellular responses to DNA damage $(21,28)$. ATM is usually activated through the 
Table II. Distribution and statistical analysis of p53bp1 D353E (53BP1 1236G>C) genotypes.

\begin{tabular}{lrrrrc}
\hline & GG, $\mathrm{n}(\%)$ & $\mathrm{GC}, \mathrm{n}(\%)$ & $\mathrm{CC}, \mathrm{n}(\%)$ & P-value & OR (95\% CI) \\
\hline All Cases & & & & & Reference \\
Normal (n=280) & $99(35.4)$ & $132(47.1)$ & $49(17.5)$ & & 0.093 \\
All lesions (n=149) & $65(43.6)$ & $63(42.3)$ & $21(14.1)$ & $1.42(0.94-2.12)$ \\
LSIL (n=70) & $33(47.1)$ & $27(38.6)$ & $10(14.3)$ & 0.069 & $1.63(0.96-2.77)$ \\
HSIL/CIS (n=70) & $29(41.4)$ & $32(45.7)$ & $9(12.9)$ & 0.346 & $1.29(0.76-2.20)$ \\
ICC (n=9) & $3(33.3)$ & $4(44.4)$ & $2(22.2)$ & 0.602 & $0.91(0.22-3.74)$ \\
\hline
\end{tabular}

LSIL, low-grade squamous intraepithelial lesion; HSIL, high-grade squamous intraepithelial lesion; ICC, invasive cervical cancer; Chi-square analysis $\left(\chi^{2}\right)$ was performed by comparing $\mathrm{C}$ carrier vs. GG homozygous; P, Pearson $\chi^{2}$; OR, odds ratio; CI, confidence interval.

Table III. Distribution and statistical analysis of ATM D1853N (ATM 5557G>A) genotypes.

\begin{tabular}{lrrrcc}
\hline & GG, n (\%) & GA, n (\%) & AA, n (\%) & P-value & OR (95\% CI) \\
\hline All Cases & & & & & Reference \\
Normal (n=280) & $194(69.3)$ & $79(28.2)$ & $7(2.5)$ & & $1.39(0.89-2.19)$ \\
All lesion (n=149) & $113(75.8)$ & $31(20.8)$ & $5(3.4)$ & 0.152 & $1.94(1.01-3.74)$ \\
LSIL (n=70) & $57(81.4)$ & $9(12.9)$ & $4(5.7)$ & 0.044 & $1.03(0.59-1.83)$ \\
HSIL/CIS (n=70) & $49(70.0)$ & $20(28.6)$ & $1(1.4)$ & 0.908 & $1.55(0.32-7.62)$ \\
ICC (n=9) & $7(77.8)$ & $2(22.2)$ & - & 0.449 & \\
\hline
\end{tabular}

LSIL, low-grade squamous intraepithelial lesion; HSIL, high-grade squamous intraepithelial lesion; ICC, invasive cervical cancer; Chi-square analysis $\left(\chi^{2}\right)$ was performed by comparing A carrier vs. GG homozygous P, Pearson $\chi^{2}$; OR, odds ratio; CI, confidence interval.

p53-dependent pathway mainly by the 53BP1 and leads to a complex pathway of different events which will arrest the cell cycle and initiate DNA repair processes $(24,27,29,46)$. When DNA repair processes are inactivated or deficiently activated, cell cycle arrest and DNA repair might not occur, and cells start to accumulate errors promoting genetic instability, which can lead to the development of cancer (18). Recently, polymorphisms on 53BP1 and ATM genes were studied for their role on cancer development, and since oncogenic viruses might interact with these proteins there is a great need to evaluate the possible role of polymorphisms on these proteins in viral associated cancer development.

53BP1 C1236G polymorphism. It has been suggested that a 53BP1 genetic polymorphism involving the transition $\mathrm{C} \rightarrow \mathrm{G}$ at position 1236, leading to an amino acid shift (D353E) on the BRCT domain of p53bp1 (44), interferes with the ability to interact with the DNA-binding core of p53 $(19,22,27)$. Therefore, $\mathrm{p} 53$-dependent DNA repair mechanisms might not be activated efficiently (47). This polymorphism was recently associated with increased risk for breast cancer development in individuals carrying the Pro/Pro genotype of the p53 codon 72 (43). Considering the cervical carcinogenesis model, if the affinity of the p53BP1 for p53 is lost, HPV-infected cells will be more prone to HPV E6-mediated p53 degradation, increasing the risk of cancer development. Our study revealed no significant association between the 53BP1 genotypes and the development of cervical cancer. A crude analysis of OR reveals a tendency for increased risk of LSIL, nevertheless, in our study no statistically significant results were obtained.

Surprisingly, our study revealed significant differences on the p53bp1 D353E genotypes comparing our control population with data from other studies: Frank et al reported in a German population that $9.9 \%$ were GG homozygous, $42.6 \%$ were GC and $47.6 \%$ were CC homozygous (44); and Ma et al reported $18.2 \%$ as GG homozygous, $50.9 \%$ GC and $30.9 \%$ were CC homozygous in a Chinese population (43). Therefore it is necessary to point out that these results may be influenced by ethnic variables.

ATM G5557A polymorphism. Previous reports have shown that a $\mathrm{G}>\mathrm{A}$ transition at position 5557, which produces an amino acid shift (D1853N), is supposed to affect the normal splicing of ATM leading to the expression of a less effective protein $(34-36,40)$. In normal conditions, ATM, one of the major sensors of DNA damage, activates a complex pathway of different events, leading to the cell cycle checkpoint activation and arrest for DNA repair (16). When activation of ATM does not occur efficiently, cell cycle arrest and DNA repair are void and the accumulation of DNA errors, such as, integration of DNA sequences contribute to cellular instability, that can lead to the development of neoplastic cells. Studies revealed that the 5557A is associated with hereditary non-polyposis colorectal cancer in carriers of germline MLH1 and MSH2 
mutations (41), and with the development of bilateral breast cancer (36). Our study revealed an increased risk for the ATM GG homozygous to the development of LSIL (OR=1.94; $\mathrm{p}=0.044)$. Although, logistic regression adjusted for age revealed no statistical significant differences, our results reveal that this polymorphism should be further studied to clarify its role in the development of cervical cancer.

In conclusion, over the past 10 years, our group has been studying the role of genetic polymorphism in cancer development (48-54). This is the first study to evaluate the role of the ATM D1853N (5557G >A) and p53bp1 D353E $(1236 \mathrm{C}>\mathrm{G})$ polymorphisms in the development of cervical cancer in Portugal.

Although we did not find significant differences, our data reveal a trend for increased risk of LSIL of both polymorphisms that, if corroborated by a study with higher number of samples, could contribute to clarify if LSIL lesions coud be considered only HPV-infected cells or a true pre-cancer lesion. Hence, our results support the need for further molecular studies to evaluate the role of polymorphism on the DNA damage repair pathways to the predisposition to cervical cancer.

\section{References}

1. Ferlay J, Shin HR, Bray F, Forman D, Mathers C and Parkin DM GLOBOCAN 2008, Cancer Incidence and Mortality Worldwide: IARC CancerBase No. 10. IARC Press, Lyon, 2008.

2. Frazer IH: Prevention of cervical cancer through papillomavirus vaccination. Nat Rev Immunol 4: 46-54, 2004.

3. Sankaranarayanan R and Ferlay J: Worldwide burden of gynaecological cancer: the size of the problem. Best Pract Res Clin Obstet Gynaecol 20: 207-225, 2006.

4. Vousden KH: Human papillomaviruses and cervical carcinoma. Cancer Cells 1: 43-50, 1989.

5. Vousden KH: Human papillomavirus oncoproteins. Semin Cancer Biol 1: 415-424, 1990.

6. zur Hausen H: Human papillomaviruses in the pathogenesis of anogenital cancer. Virology 184: 9-13, 1991.

7. Munoz N, Bosch FX, de Sanjose S, et al: Risk factors for cervical intraepithelial neoplasia grade III/carcinoma in situ in Spain and Colombia. Cancer Epidemiol Biomarkers Prev 2: 423-431, 1993

8. Munoz N, Castellsague X, de Gonzalez AB and Gissmann L: Chapter 1: HPV in the etiology of human cancer. Vaccine 24 (Suppl 3): S1-S10, 2006

9. Bosch FX, Munoz N, de Sanjose S, et al: Human papillomavirus and cervical intraepithelial neoplasia grade III/carcinoma in situ: a case-control study in Spain and Colombia. Cancer Epidemiol Biomarkers Prev 2: 415-422, 1993.

10. Franco EL, Rohan TE and Villa LL: Epidemiologic evidence and human papillomavirus infection as a necessary cause of cervical cancer. J Natl Cancer Inst 91: 506-511, 1999.

11. Castellsague X, Bosch FX and Munoz N: Environmental co-factors in HPV carcinogenesis. Virus Res 89: 191-199, 2002.

12. Matos A, Moutinho J, Pinto D and Medeiros R: The influence of smoking and other cofactors on the time to onset to cervical cancer in a southern European population. Eur J Cancer Prev 14 485-491, 2005.

13. Medeiros R, Prazeres H, Pinto D, et al: Characterization of HPV genotype profile in squamous cervical lesions in Portugal, a southern European population at high risk of cervical cancer. Eur J Cancer Prev 14: 467-471, 2005.

14. Sanlioglu S, Benson P and Engelhardt JF: Loss of ATM function enhances recombinant adeno-associated virus transduction and integration through pathways similar to UV irradiation. Virology 268: 68-78, 2000.

15. Dehart JL, Andersen JL, Zimmerman ES, et al: The ataxia telangiectasia-mutated and Rad3-related protein is dispensable for retroviral integration. J Virol 79: 1389-1396, 2005.

16. Skalka AM and Katz RA: Retroviral DNA integration and the DNA damage response. Cell Death Differ 12 (Suppl 1): S971-S978, 2005 .
17. Pett $\mathrm{M}$ and Coleman $\mathrm{N}$ : Integration of high-risk human papillomavirus: a key event in cervical carcinogenesis? J Pathol 212: 356-367, 2007.

18. Costa S, Pinto D, Pereira D, et al: DNA repair polymorphisms might contribute differentially on familial and sporadic breast cancer susceptibility: a study on a Portuguese population. Breast Cancer Res Treat 103: 209-217, 2007.

19. Bork P, Hofmann K, Bucher P, Neuwald AF, Altschul SF and Koonin EV: A superfamily of conserved domains in DNA damage-responsive cell cycle checkpoint proteins. FASEB J 11: 68-76, 1997.

20. Meulmeester E, Pereg Y, Shiloh Y and Jochemsen AG: ATMmediated phosphorylations inhibit Mdmx/Mdm2 stabilization by HAUSP in favor of p53 activation. Cell Cycle 4: 1166-1170, 2005.

21. Shiloh Y: ATM and related protein kinases: safeguarding genome integrity. Nat Rev Cancer 3: 155-168, 2003.

22. Callebaut I and Mornon JP: From BRCA1 to RAP1: a widespread BRCT module closely associated with DNA repair. FEBS Lett 400: 25-30, 1997

23. Schultz LB, Chehab NH, Malikzay A and Halazonetis TD: p53 binding protein 1 (53BP1) is an early participant in the cellular response to DNA double-strand breaks. J Cell Biol 151: 1381-1390, 2000.

24. Rappold I, Iwabuchi K, Date T and Chen J: Tumor suppressor p53 binding protein 1 (53BP1) is involved in DNA damage-signaling pathways. J Cell Biol 153: 613-620, 2001.

25. Anderson L, Henderson C and Adachi Y: Phosphorylation and rapid relocalization of 53BP1 to nuclear foci upon DNA damage. Mol Cell Biol 21: 1719-1729, 2001.

26. Mochan TA, Venere M, DiTullio RA Jr and Halazonetis TD: 53BP1 and NFBD1/MDC1-Nbs1 function in parallel interacting pathways activating ataxia-telangiectasia mutated (ATM) in response to DNA damage. Cancer Res 63: 8586-8591, 2003.

27. Mochan TA, Venere M, DiTullio RA Jr and Halazonetis TD: 53BP1, an activator of ATM in response to DNA damage. DNA Repair (Amst) 3: 945-952, 2004.

28. Khanna KK and Chenevix-Trench G: ATM and genome maintenance: defining its role in breast cancer susceptibility. J Mammary Gland Biol Neoplasia 9: 247-262, 2004.

29. Khanna KK, Lavin MF, Jackson SP and Mulhern TD: ATM, a central controller of cellular responses to DNA damage. Cell Death Differ 8: 1052-1065, 2001.

30. Gatti RA, Berkel I, Boder E, et al: Localization of an ataxia-telangiectasia gene to chromosome 11q22-23. Nature 336: 577-580, 1988.

31. Chen G and Lee EYHP: The product of the ATM gene is a 370-kDa nuclear phosphoprotein. J Biol Chem 271: 33693-33697, 1996.

32. Uziel T, Savitsky K, Platzer M, et al: Genomic Organization of the ATM gene. Genomics 33: 317-320, 1996.

33. Lavin MF and Shiloh Y: The genetic defect in ataxia-telangiectasia. Annu Rev Immunol 15: 177-202, 1997.

34. Thorstenson YR, Roxas A, Kroiss R, et al: Contributions of ATM mutations to familial breast and ovarian cancer. Cancer Res 63: 3325-3333, 2003.

35. Maillet P, Vaudan G, Chappuis P and Sappino A: PCR-mediated detection of a polymorphism in the ATM gene. Mol Cell Probes 13: 67-69, 1999.

36. Thorstenson YR, Shen P, Tusher VG, et al: Global analysis of ATM polymorphism reveals significant functional constraint. Am J Hum Genet 69: 396-412, 2001.

37. Angele S, Falconer A, Edwards SM, et al: ATM polymorphisms as risk factors for prostate cancer development. Br J Cancer 91: 783-787, 2004.

38. Angele S, Romestaing P, Moullan N, et al: ATM haplotypes and cellular response to DNA damage: association with breast cancer risk and clinical radiosensitivity. Cancer Res 63: 8717-8725, 2003.

39. Heikkinen K, Rapakko K, Karppinen SM, Erkko H, Nieminen P and Winqvist R: Association of common ATM polymorphism with bilateral breast cancer. Int J Cancer 116: 69-72, 2005.

40. Tapia T, Sanchez A, Vallejos M, et al: ATM allelic variants associated to hereditary breast cancer in 94 Chilean women: susceptibility or ethnic influences? Breast Cancer Res Treat 107: 281-288, 2008.

41. Maillet $\mathrm{P}$, Chappuis $\mathrm{PO}$, Vaudan $\mathrm{G}$, et al: A polymorphism in the ATM gene modulates the penetrance of hereditary non-polyposis colorectal cancer. Int J Cancer 88: 928-931, 2000.

42. Meier M, den Boer ML, Hall AG, et al: Relation between genetic variants of the ataxia telangiectasia-mutated (ATM) gene, drug resistance, clinical outcome and predisposition to childhood T-lineage acute lymphoblastic leukaemia. Leukemia 19: 1887-1895, 2005. 
43. Ma H, Hu Z, Zhai X, et al: Joint effects of single nucleotide polymorphisms in P53BP1 and p53 on breast cancer risk in a Chinese population. Carcinogenesis 27: 766-771, 2006.

44. Frank B, Hemminki K, Bermejo JL, et al: TP53-binding protein variants and breast cancer risk: a case-control study. Breast Cancer Res 7: R502-R505, 2005.

45. Daniel R, Kao G, Taganov K, et al: Evidence that the retroviral DNA integration process triggers an ATR-dependent DNA damage response. Proc Natl Acad Sci USA 100: 4778-4783, 2003.

46. Iwabuchi K, Basu BP, Kysela B, et al: Potential role for 53BP1 in DNA end-joining repair through direct interaction with DNA. J Biol Chem 278: 36487-36495, 2003.

47. Derbyshire DJ, Basu BP, Serpell LC, et al: Crystal structure of human 53BP1 BRCT domains bound to p53 tumour suppressor. EMBO J 21: 3863-3872, 2002.

48. Medeiros R, Morais A, Vasconcelos A, et al: The role of vitamin $\mathrm{D}$ receptor gene polymorphisms in the susceptibility to prostate cancer of a southern European population. J Hum Genet 47: 413-418, 2002.

49. Pinto D, Vasconcelos A, Costa S, et al: HER2 polymorphism and breast cancer risk in Portugal. Eur J Cancer Prev 13: 177-181, 2004.
50. Cardoso CS, Araujo HC, Cruz E, et al: Haemochromatosis gene (HFE) mutations in viral-associated neoplasia: Linkage to cervical cancer. Biochem Biophys Res Commun 341: 232-238, 2006.

51. Santos AM, Sousa H, Catarino R, et al: TP53 codon 72 polymorphism and risk for cervical cancer in Portugal. Cancer Genet Cytogenet 159: 143-147, 2005.

52. Pereira C, Pimentel-Nunes P, Brandao C, Moreira-Dias L, Medeiros R and Dinis-Ribeiro M: COX-2 polymorphisms and colorectal cancer risk: a strategy for chemoprevention. Eur J Gastroenterol Hepatol 22: 607-613, 2010.

53. Sousa H, Pando M, Breda E, Catarino R and Medeiros R: Role of the MDM2 SNP309 polymorphism in the initiation and early age of onset of nasopharyngeal carcinoma. Mol Carcinog 50: 73-79, 2011.

54. Sousa H,Breda E, Santos AM, Catarino R, Pinto D and Medeiros R: Genetic risk markers for nasopharyngeal carcinoma in Portugal: tumor necrosis factor alpha $-308 \mathrm{G}>\mathrm{A}$ polymorphism. DNA Cell Biol 30: 99-103, 2011. 